\title{
Symbol Search Subtest (WAIS-IV)
}

National Cancer Institute

\section{Source}

National Cancer Institute. Symbol Search Subtest (WAIS-IV). NCI Thesaurus. Code

C120366.

A subtest of the Wechsler Adult Intelligence Scale, 4th Edition that measures processing speed, short-term visual memory, visual-motor coordination, cog nitive flexibility, visual discrimination, psychomotor speed, and speed of mental operation. The subject scans a search group and indicates whether one of the symbols in the target group matches. 